\title{
Assessing the external validity of a randomized controlled trial of anthelminthics in mothers and their children in Entebbe, Uganda
}

\author{
James D Millard ${ }^{1 *}$, Lawrence Muhangi², Moses Sewankambo², Juliet Ndibazza², Alison M Elliott ${ }^{2,3}$
} and Emily $L$ Webb ${ }^{3}$

\begin{abstract}
Background: The 'external validity' of randomized controlled trials is an important measure of quality, but is often not formally assessed. Trials concerning mass drug administration for helminth control are likely to guide public health policy and careful interpretation of their context is needed. We aimed to determine how representative participants in one such trial were of their community. We explore implications for trial interpretation and resulting public health recommendations.

Methods: The trial assessed was the Entebbe Mother and Baby Study (EMaBS), a trial of anthelminthic treatment during pregnancy and early childhood. In a novel approach for assessing external validity, we conducted a two-stage cluster sample community survey within the trial catchment area and compared characteristics of potentially-eligible community children with characteristics of children participating in the trial.

Results: A total of 173 children aged three to five-years-old were surveyed from 480 households. Of children surveyed, we estimated that mothers of $60 \%$ would have been eligible for recruitment, and of these, $31 \%$ had actually been enrolled. Children surveyed were compared to 199 trial children in the same age group reviewed at annual trial visits during the same time period. There were significant differences in ethnicity between the trial participants and the community children, and in socioeconomic status, with those in the trial having, on average, more educated parents and higher maternal employment. Trial children were less likely to have barefoot exposure and more likely to use insecticide-treated bed nets. There were no significant differences in numbers of reported illness events over the last year.

Conclusions: The trial had not enrolled all eligible participants, and those enrolled were of higher socioeconomic status, and had lower risk of exposure to the parasitic infections targeted by the trial interventions. It is possible the trial may have underestimated the absolute effects of anthelminthic treatment during pregnancy and early childhood, although the fact that there were no differences in reported incidence of common infectious diseases (one of the primary outcomes of EMaBS) between the two groups provides reassurance. Concurrent community surveys may be an effective way to test the external validity of trials.
\end{abstract}

EMaBS Trial registration: ISRCTN32849447, registered 22 July 2005

Keywords: Helminths, Anthelminthics, External validity, Generalizability, Cluster sample community survey, Uganda

\footnotetext{
* Correspondence: j.millard@bsms.ac.uk

'Department of Global Health, Division of Clinical Medicine, Brighton and

Sussex Medical School, Falmer, Brighton BN1 9PX, UK

Full list of author information is available at the end of the article
} 


\section{Background}

The rise of evidence-based medicine has seen much emphasis placed on the internal validity of clinical trials but less attention has been given to external validity. Measures adopted for ensuring internal validity include the design of a trial which is appropriately powered to detect a clinically significant effect, the use of a control group selected by randomization and the 'blinding' of both participants and investigators to the intervention. Statistical analysis of the trial results then allows the classification of data on the basis of generally accepted levels of 'significance' $[1,2]$. However, there have been increasing calls to take into account other factors when assessing the quality of evidence generated by trials [3-7]. These include biological plausibility, reproducibility and external validity [8]. External validity can be considered as the extent to which the results can be generalized to other circumstances. Whilst important, these factors may not have received the attention they deserve because their quality is not always easy to assess. However, failure to take these factors into account may limit a study's usefulness. The implementation of findings that are not clearly applicable to the population in question has been called 'evidence-biased medicine' [9]. Increased awareness of external validity as a measure of study quality has led to its incorporation into several highprofile frameworks for the reporting and assessment of clinical trials [10-12]. The assessment of external validity is particularly important for trials in resource-poor settings, as these may be used to guide wide-ranging public health policy decisions, often in several settings or countries [13-15].

We aimed to assess the 'external validity' of the Entebbe Mother and Baby Study (ISRCTN32849447), a trial designed to investigate the effects of anthelminthic treatment in pregnancy and in childhood [16]. The primary outcomes included immunological responses to immunization and incidence of infectious and allergic disease in early childhood. This trial has now been reported and demonstrated a possible benefit of anthelminthic treatment during pregnancy for maternal anaemia, restricted to women with moderate to heavy hookworm infection, and a reduction in malaria incidence among children receiving quarterly anthelminthic treatment. However, there were none of the expected benefits for anaemia, birth weight, perinatal mortality, infant mortality or infant responses to immunizations. By contrast, there was an apparent adverse effect on infantile eczema [17-20].

There are relatively few studies which aim to assess the external validity of clinical trials. Most published studies focus on assessing the number of people included in the trial, as a proportion of those who would have been eligible for participation in the trial given the trial's inclusion and exclusion criteria [21-27]. Other published studies rate trials on a scoring system devised for the purpose $[28,29]$, assess the adequacy of reporting of exclusion criteria [30,31] or other generalizability measures [14], compare inferences derived from randomized controlled trial data with inferences derived from populationbased studies addressing similar outcomes [32], compare outcomes between persons included and excluded from a trial $[33,34]$ or assess the representation of certain groups $[35,36]$. Here, we report a novel approach to assess the external validity of a trial. Specifically, we conducted a community survey to assess whether participants in the Entebbe Mother and Baby Study were representative of the trial's target population. By conducting a community-wide survey in which any appropriately aged child in the trial catchment area could potentially be enrolled, we hope to offer a more comprehensive assessment of external validity than studies to date. Our findings have implications for the generalizability of this trial, but also demonstrate an approach that may be of use in assessing the external validity of other trials.

\section{Methods \\ Setting}

The catchment area for the Entebbe Mother and Baby Study (EMaBS) was comprised of the Entebbe Municipality and Katabi sub-country, a peninsula on the northern shore of Lake Victoria, Uganda. Entebbe town is located approximately $40 \mathrm{~km}$ southwest of the capital, Kampala, has a population of approximately 90,500 and is the site of Uganda's main international airport. Katabi sub-county borders Entebbe Municipality, has a population of approximately 59,000 and consists of semi-urban, rural and fishing communities. The EMaBS trial recruited pregnant women between April 2003 and November 2005. At the time of this investigation (between July and August 2008), EMaBS cohort children were aged three, four and five years. We therefore conducted a survey within the same catchment area, consisting of three, four and five-year-old children, both male and female.

\section{Study design}

The community survey used a sampling strategy designed to reduce bias within a setting with limited prior demographic data. The study area comprised 47 administrative units known as wards. Census data detailing the number of households in each ward was available. A sample of 15 wards within the survey area was selected by random number generation, with probability of selection being proportional to the number of households. It was possible for one ward to be selected twice. Each ward was then mapped onto satellite imagery of the area with the help of locally available maps. Uninhabitable areas were excluded from mapping. The wards were divided into segments of 
equal geographical size (the same size across all wards) based on lines of latitude and longitude (degrees, minutes, seconds position format). These segments were then numbered and four segments from each ward were randomly selected using random number generation. The midpoint of each segment was identified by its coordinates and this was used as the starting point for sampling. The starting point was identified using a geographic information system (GIS) device (eTrex ${ }^{\oplus}$, Garmin ${ }^{\mathrm{T} M}$ Ltd, Kansas, United States) and the nearest house selected for sampling. Eight houses were then surveyed sequentially from this point, the next house to be sampled being the nearest to the previous house. A household was defined as a habitable roofed structure whose primary function was residence or, if used for dual purposes, had at least one active resident using the structure as their primary residence. In selected households that included a three, four or five-year old child, the parent or guardian was counselled and provided with written information in English and the vernacular of the area prior to obtaining written consent. If two or more eligible children lived in the same house, they were all surveyed if possible.

A questionnaire was then administered for each child. This was designed to match with data collected at the yearly trial visits undertaken by children enrolled in the Entebbe Mother and Baby Study, in order to obtain comparable information from both sources. In addition, during the period of the community survey supplementary information sheets were completed by trial participants during these yearly visits. These covered questions asked in the community survey but not routinely asked in the trial, or which had been asked in screening at enrolment into the trial, but were felt likely to have changed since that time.

\section{Recruitment to EMaBS and community participation}

EMaBS trial participants were recruited at the antenatal clinic at Entebbe Hospital over a two and a half year period. At the same time, the community was sensitized to the study. The mayor of Entebbe and sub-county chief of Katabi were informed and the research team visited all villages in the catchment area and held meetings with the local council (LC) leaders. LC leaders were asked to select community field workers, who were trained in simple data collection and subsequently followed up on participating children every two weeks until they were five-years-old. They met monthly and provided the main link between the research team and the community throughout the study period.

Inclusion criteria for the EMaBS trial required women to be resident in the study area, attending the Entebbe Hospital antenatal clinic and intending to give birth at the hospital, with no age limits. The exclusion criteria for the trial included not wishing to participate, not being willing to receive an HIV result, bloody diarrhoea, previous adverse reaction to anthelminthics or sulfadoxine-pyrimethamine $\left(\right.$ Fansidar $\left.^{\mathrm{TM}}\right)$, already having a child in the trial, antenatal abnormalities, failure to complete screening or re-attend for enrolment, not being pregnant and anaemia (hemoglobin $<8 \mathrm{~g} / \mathrm{dL}$ ).

\section{Eligibility and uptake assessment}

In the survey, we first aimed to assess what proportion of community children would have been potentially eligible for EMaBS trial participation. Children were deemed to have been potentially eligible if, at the time of the child's birth, the mother was resident within the study area and attended the Entebbe Hospital antenatal clinic. We then aimed to estimate what proportion of potentially eligible children had actually been enrolled in the trial. We were unable to directly assess the impact of the other EMaBS inclusion and exclusion criteria.

\section{Outcomes}

Socio-demographic characteristics: The outcomes assessed were primary carer/s, maternal and paternal age and health status, level of maternal and paternal education, maternal employment and wage, maternal tribe and other socioeconomic parameters (including housing materials, crowding, water and electricity provision). These factors are unlikely to have been affected by the trial intervention and therefore reflect inherent characteristics of the study population.

Disease risk factors and comorbidities: Outcomes assessed were barefoot exposure, lake exposure (both risk factors for helminth infection), mosquito net usage and insecticide-treatment of household nets (risk factors for malaria).

Diseases and anthropometry outcomes were as follows: we recorded self-reported disease episodes of malaria, diarrhoea, pneumonia, measles and tuberculosis. We did not ask directly about HIV because of the limitations placed on confidentiality in the field setting and concerns over the reliability of any results obtained. We also measured height, weight, mid to upper arm circumference and head circumference. These outcomes may have been influenced by the trial interventions.

\section{Statistical analysis}

Data were analyzed using Stata version 12 (StataCorp, Texas, United States). Data from the youngest of each pair or group of siblings in the community survey were excluded from the analysis, in order to make the inclusion criteria comparable with EMaBS (where one of the exclusion criteria was having a child already in the trial). Clustering at the ward and segment level was taken into account in the analysis. Clustering at the household level was not allowed for in the analysis due to the small 
number of households remaining with multiple children after younger siblings were excluded from the analysis. The svy commands in Stata were used to allow for the clustering. Distributions of parental and child characteristics in the two groups were first compared using simple tabulations, with design-based Pearson's F statistics calculated to test for differences in characteristics between the community survey and EMaBS children. Logistic regression was used to calculate crude and adjusted odds ratios (ORs) and associated 95\% confidence intervals (CIs), allowing for the sampling design. Multivariable logistic regression analysis was conducted to control for potential confounding. A hierarchical approach was used to decide which variables should be treated as potential confounders in the multivariable analysis. Maternal and paternal sociodemographic parameters were considered as potential confounders for each other, for household characteristics, for disease risk factors and comorbidities, and for diseases and anthropometry. Household characteristics were considered as potential confounders for each other, for disease risk factors and comorbidities and for diseases and anthropometry. Finally, disease risk factors and comorbidities were considered as potential confounders for diseases and anthropometry.

\section{Ethical approval}

Both EMaBS and the community survey received ethical approval from the Science and Ethics Committee of the Uganda Virus Research Institute (GC/127), Uganda National Council for Science and Technology (MV 625) and the London School of Hygiene and Tropical Medicine ethics committee (07/303).

\section{Results}

In total, 480 households were surveyed; eight households from each of four locations in 15 wards. The breakdown of these is provided in Figure 1. One hundred and seventy three children were eligible for inclusion in the analysis. During the survey period 199 trial children visited the trial clinic, of whom 128 completed supplementary information questionnaires. There were no differences in characteristics of those who completed supplementary questionnaires compared to those who did not.

Of the 173 children seen in the community, 104 (60\%) had mothers who would have been potentially eligible for recruitment into the trial. Of the remaining children, 38 (55\%) had mothers who were not resident in Entebbe or Katabi at the time of delivery, an additional 28 (41\%) had mothers who did not receive antenatal care at Entebbe

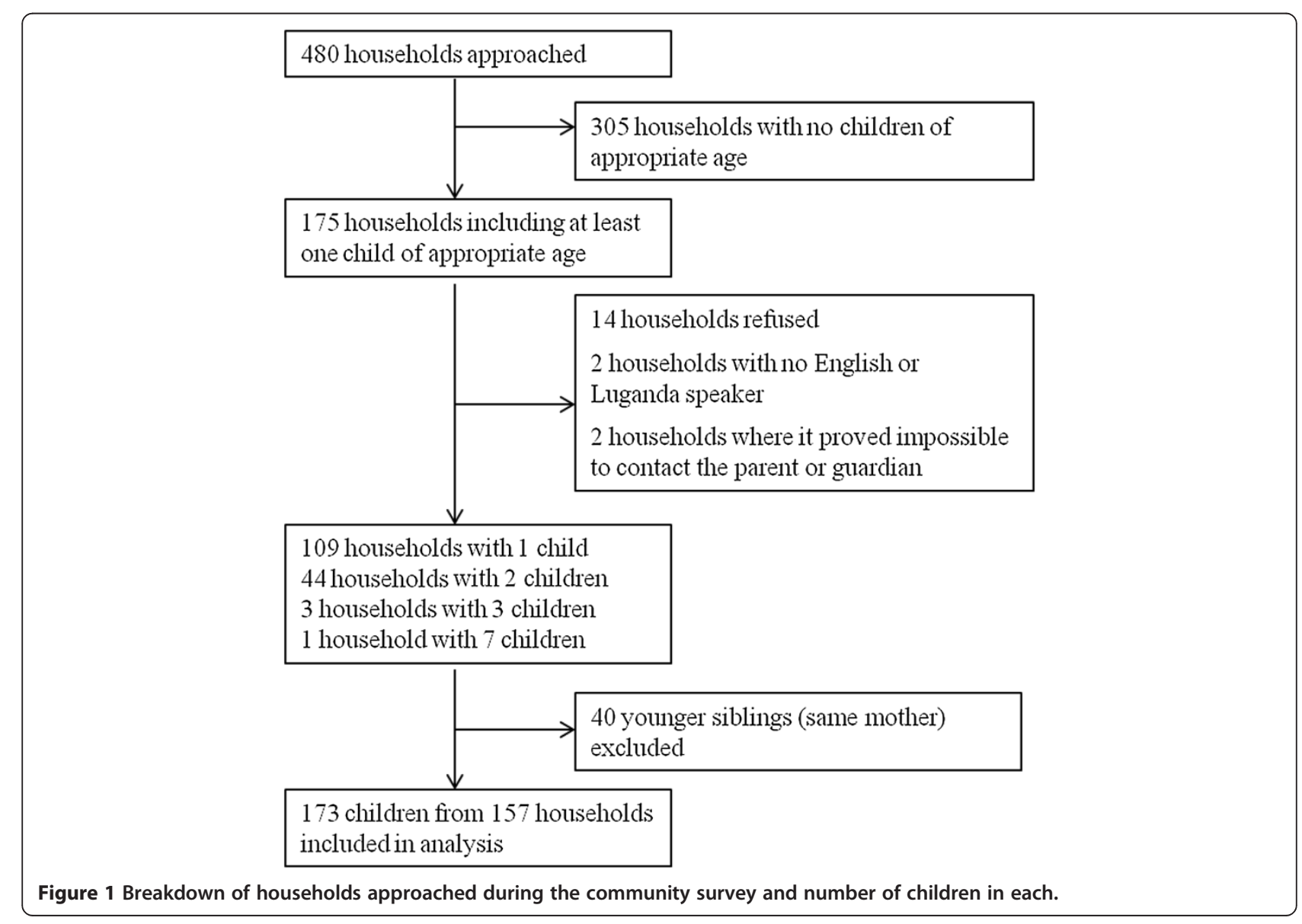


Hospital and were therefore not available for recruitment, and there was no information available on where mothers had received antenatal care for 3 (4\%). Of the 104 children who were potentially eligible for inclusion, 32 (31\%) were in the trial.

There were significant differences between the ethnic makeup of the two populations, based on the mother's tribe. Of particular note only half the mothers in the trial were Buganda compared to $65 \%$ in the community, and being a member of the Banyankole, Batoro or Banyarwanda tribes was twice as common in the trial mothers (Table 1).

Levels of both maternal and paternal education were, on average, higher amongst trial children (Table 1). There was no significant difference in parental health or primary carer between the two groups (data not shown). In crude analysis mothers in the trial were, on average, significantly older than those in the community, but this difference was no longer significant after adjusting for tribe and education (Table 2). There was no significant difference in the mean paternal age. There were significant differences in maternal employment and income. Mothers of trial children were more than twice as likely to be employed, and subsequently tended to have a higher income, although income was no longer significantly different between the two groups once maternal employment was taken into account.

Trial children were more likely to live in houses with more than three people per room and more likely to live in houses with metal or mud walls than community survey children (Table 2 ). In crude analysis, there was a significant difference in fuel source between the two groups, but this was no longer significant after adjustment for other household characteristics $(P=0.33)$. There were no significant differences in roofing materials, electricity or water source between the two groups (Table 1).

There were several differences in disease risk factors between the community and trial children (Tables 1, 2). Reported mosquito net usage was markedly higher in the trial group, with an increased likelihood of the net being treated. Reported frequent barefoot exposure was higher in the community and lake exposure was similar in the two groups (Table 1). There was no significant difference between reported disease measures of malaria, slide-proven malaria or pneumonia (Table 1). Reported diarrhoea was more common among trial children, although this difference was not significant after adjusting for other parental and household factors $(P=0.26)$. Reported measles, although rare, was more common in community children (Table 2).

\section{Discussion}

We have presented a community survey as a novel method for assessing aspects of the external validity of a randomized controlled trial. We found that EMaBS trial participants were on average, more likely to have parents with higher levels of education and who were in employment, more likely to come from non-local tribal groups, more likely to sleep under a bed-net and less likely to have barefoot exposure (a risk factor for helminths) than children in the target population for the trial. However, we found no differences in reported episodes of common childhood diseases between trial participants and children in the community survey. We estimate that $31 \%$ of eligible children in the community were enrolled in the trial, and although it was not possible to assess all trial exclusion criteria in the community survey, refusal and exclusion criteria are unlikely to account for the lack of enrolment of all the remaining children.

Under a fifth of children in the community had been enrolled in the trial. Approximately 22\% of children were ineligible on the basis of non-residency at the time of birth, and these children may have differed in important ways from those who had not recently migrated. This is an unavoidable factor when considering the nonrepresentativeness of trials to their community. It is possible that migration into a trial area, particularly if large and sustained, may account for a significant proportion of any non-representativeness and this highlights the need to interpret the results of trials carefully in the light of shifting demographic patterns. A similar proportion of children were ineligible because their mothers received antenatal care outside of the hospital setting, a group previously noted to differ from those who did receive hospital-based antenatal care in this area [37]. Our survey was not powered to assess whether those children excluded in this way were significantly different from those eligible for the trial. However, the relatively high level of hospital-based antenatal care is reassuring and provides support for the recruitment strategy used in this trial, hence lending support to its external validity.

Approximately $60 \%$ of mothers of children in the community survey would have been eligible for recruitment into EMaBS on the basis of residence and of antenatal care in Entebbe Hospital, and 31\% of these were enrolled in the trial. Non-participation could have been secondary to refusal, exclusion on the basis of trial exclusion criteria or not having been approached for recruitment into the trial. In comparison, data from the EMaBS trial itself (Figure 2) shows that of 11,783 mothers initially assessed for inclusion in the trial, 5,388 (46\%) were resident in and obtained antenatal care in Entebbe, planned on delivering in Entebbe hospital, and did not already have a baby in the trial. Of these, 2515 (47\%) were subsequently enrolled [18]. However, the discrepancy between the figures of $31 \%$ and $47 \%$ implies a failure to fully assess all potentially eligible mothers at the antenatal clinic, most likely as a result of the heavy patient 
Table 1 Comparison of characteristics of EMaBS trial annual visit children and community survey children

\begin{tabular}{|c|c|c|c|c|}
\hline & $\begin{array}{l}\text { Trial annual visit } \\
(n=199)\end{array}$ & $\begin{array}{l}\text { Community survey } \\
(\mathrm{n}=173)\end{array}$ & OR $(95 \% \mathrm{Cl})^{1}$ & $P^{1}(P$ trend $)$ \\
\hline \multicolumn{5}{|l|}{ Sociodemographic variables ${ }^{2}$} \\
\hline \multicolumn{5}{|l|}{ Maternal tribe } \\
\hline Baganda & $99(50 \%)$ & $110(65 \%)$ & 1 & 0.05 \\
\hline Banyankole/Batoro/Banyarwanda & 37 (19\%) & $17(10 \%)$ & $0.41(0.20,0.87)$ & \\
\hline Basoga & $11(6 \%)$ & $6(4 \%)$ & $0.49(0.16,1.50)$ & \\
\hline Other & $52(27 \%)$ & $37(22 \%)$ & $0.64(0.34,1.21)$ & \\
\hline \multicolumn{5}{|l|}{ Maternal education (mv: 0, 13) } \\
\hline None & $8(4 \%)$ & $22(14 \%)$ & $4.43(1.85,10.57)$ & $<0.001$ \\
\hline Primary & $103(52 \%)$ & $64(40 \%)$ & 1 & $(0.08)$ \\
\hline Secondary & $67(34 \%)$ & $68(43 \%)$ & $1.63(0.97,2.76)$ & \\
\hline Tertiary & $21(11 \%)$ & $6(4 \%)$ & $0.46(0.17,1.21)$ & \\
\hline \multicolumn{5}{|l|}{ Paternal education (mv: 37, 38) } \\
\hline None/primary & $31(19 \%)$ & $46(34 \%)$ & 1 & $<0.001$ \\
\hline Secondary & 79 (49\%) & $75(56 \%)$ & $0.64(0.36,1.14)$ & $(<0.001)$ \\
\hline Tertiary & $52(32 \%)$ & $14(10 \%)$ & $0.18(0.09,0.37)$ & \\
\hline Maternal age (mv: 0, 12) & $24.2(4.7)$ & $23.1(5.6)$ & $0.96(0.92,1.00)$ & 0.04 \\
\hline Paternal age (mv: 121, 54) & $34.8(7.1)$ & $33.8(7.4)$ & $0.98(0.95,1.02)$ & 0.33 \\
\hline \multicolumn{5}{|l|}{ Maternal employment (mv: 73, 8) } \\
\hline Unemployed & $56(44 \%)$ & $123(75 \%)$ & 1 & $<0.001$ \\
\hline Employed & $70(56 \%)$ & $42(25 \%)$ & $0.27(0.16,0.46)$ & \\
\hline \multicolumn{5}{|c|}{ Annual maternal income (Ugandan Shillings) (mv: 77, 1) } \\
\hline Zero & $67(55 \%)$ & $126(73 \%)$ & 1 & 0.002 \\
\hline $0-50000$ & $26(21 \%)$ & $15(9 \%)$ & $0.31(0.15,0.64)$ & $(0.08)$ \\
\hline $50001-100000$ & $23(19 \%)$ & $18(10 \%)$ & $0.42(0.21,0.83)$ & \\
\hline 100001- & $6(5 \%)$ & $13(8 \%)$ & $1.15(0.40,3.29)$ & \\
\hline \multicolumn{5}{|l|}{ Household circumstances } \\
\hline \multicolumn{5}{|l|}{ Crowding (mv: 74,1$)$} \\
\hline$<=3$ people/room & $77(62 \%)$ & $126(73 \%)$ & 1 & \\
\hline$>3$ people/room & $48(38 \%)$ & $46(27 \%)$ & $0.59(0.37,0.93)$ & 0.02 \\
\hline \multicolumn{5}{|l|}{ Roofing (mv: 74, 1) } \\
\hline Iron/tiles & $118(94 \%)$ & $169(98 \%)$ & 1 & \\
\hline Banana leaves/grass & $7(6 \%)$ & $3(2 \%)$ & $0.30(0.06,1.56)$ & 0.13 \\
\hline \multicolumn{5}{|l|}{ Walls (mv: 74, 1) } \\
\hline Bricks & 108 (86\%) & $164(95 \%)$ & 1 & \\
\hline Mud/metal & $17(14 \%)$ & $8(5 \%)$ & $0.31(0.10,0.92)$ & 0.03 \\
\hline \multicolumn{5}{|l|}{ Fuel source (mv: 73,1$)$} \\
\hline Firewood & $25(20 \%)$ & $27(16 \%)$ & 1 & 0.04 \\
\hline Charcoal & 89 (71\%) & 141 (82\%) & $1.47(0.67,3.22)$ & \\
\hline Paraffin/gas/elec & $12(10 \%)$ & $4(2 \%)$ & $0.31(0.08,1.16)$ & \\
\hline \multicolumn{5}{|l|}{ Electricity supply (mv: 71,1$)$} \\
\hline Yes & $60(48 \%)$ & 67 (39\%) & 1 & \\
\hline No & $66(52 \%)$ & $105(61 \%)$ & $1.42(0.81,2.50)$ & 0.21 \\
\hline
\end{tabular}




\begin{tabular}{|c|c|c|c|c|}
\hline \multicolumn{5}{|l|}{ Water source (mv: 71, 1) } \\
\hline Lake/well/borehole & $15(12 \%)$ & $14(8 \%)$ & 1 & \\
\hline Standpipe/domestic tap & $111(88 \%)$ & $158(92 \%)$ & $1.53(0.52,4.51)$ & 0.44 \\
\hline \multicolumn{5}{|l|}{ Disease risk factors } \\
\hline \multicolumn{5}{|l|}{ Barefoot exposure (mv: 71, 6) } \\
\hline Never/rarely & $47(37 \%)$ & $7(4 \%)$ & 1 & $<0.001$ \\
\hline Often & $79(63 \%)$ & $160(96 \%)$ & $13.60(5.55,33.30)$ & \\
\hline \multicolumn{5}{|l|}{ Lake exposure (mv: 71, 1) } \\
\hline Never & $108(86 \%)$ & $145(84 \%)$ & 1 & \\
\hline Ever & $18(14 \%)$ & $27(16 \%)$ & $1.12(0.59,2.13)$ & 0.74 \\
\hline \multicolumn{5}{|l|}{ Child sleeps under net (mv: 55,1$)$} \\
\hline Always & $113(78 \%)$ & $88(51 \%)$ & 1 & $<0.001$ \\
\hline Sometimes & $13(9 \%)$ & $28(16 \%)$ & $2.77(1.32,5.79)$ & $(<0.001)$ \\
\hline Never & $18(13 \%)$ & $56(33 \%)$ & $3.99(2.11,7.56)$ & \\
\hline \multicolumn{5}{|l|}{ Household nets treated? } \\
\hline None & $56(44 \%)$ & $109(94 \%)$ & 1 & $<0.001$ \\
\hline Some/all & $71(56 \%)$ & $7(6 \%)$ & $0.05(0.02,0.12)$ & \\
\hline \multicolumn{5}{|l|}{ Reported disease episodes } \\
\hline \multicolumn{5}{|l|}{ Malaria (mv: 14, 1) } \\
\hline No & $88(48 \%)$ & $74(43 \%)$ & 1 & \\
\hline Yes & $97(52 \%)$ & $98(57 \%)$ & $1.20(0.78,1.86)$ & 0.41 \\
\hline \multicolumn{5}{|l|}{ Malaria (slide proven; mv: 44, 2) } \\
\hline No & $103(66 \%)$ & $111(65 \%)$ & 1 & \\
\hline Yes & $52(34 \%)$ & $60(35 \%)$ & $1.07(0.69,1.65)$ & 0.76 \\
\hline \multicolumn{5}{|l|}{ Diarrhoea (mv: 14, 2) } \\
\hline No & $120(65 \%)$ & $130(76 \%)$ & 1 & \\
\hline Yes & $65(35 \%)$ & $41(24 \%)$ & $0.58(0.35,0.97)$ & 0.04 \\
\hline \multicolumn{5}{|l|}{ Pneumonia (mv: 7, 4) } \\
\hline No & 188 (98\%) & 164 (97\%) & 1 & \\
\hline Yes & $4(2 \%)$ & $5(3 \%)$ & $1.43(0.38,5.35)$ & 0.59 \\
\hline \multicolumn{5}{|l|}{ Measles (mv: 7, 2) } \\
\hline No & $181(94 \%)$ & $147(86 \%)$ & 1 & \\
\hline Yes & $11(6 \%)$ & $24(14 \%)$ & $2.69(1.22,5.92)$ & 0.01 \\
\hline Anthropometric measurements & Mean (SD) & Mean (SD) & & \\
\hline Weight-for-age z-score & $-0.46(0.97)$ & $-0.61(1.04)$ & $0.86(0.68,1.09)$ & 0.21 \\
\hline Height-for-age z-score & $-0.90(0.96)$ & $-0.91(1.27)$ & $0.99(0.80,1.24)$ & 0.96 \\
\hline
\end{tabular}

${ }^{1}$ Odds ratios use the trial population as the reference group and are adjusted for clustering.

$2 \mathrm{mv}$ denotes number of individuals with missing values in EMaBS and Community Survey groups, respectively.

burden at the clinic. It is possible that this could have introduced bias due to differences in characteristics of women who would be able or willing to wait for the research procedures after receiving their standard antenatal care. This would be a potential threat to this trial's external validity if a systematic bias occurred. Figure 2 also shows the reasons for which mothers were excluded from the EMaBS trial that could not be assessed in the community survey. It is possible that sociodemographic characteristics of women with these exclusion criteria differed from characteristics of those who did not meet them. If so then this could be an explanation for the different characteristics seen between the trial and community survey participants.

Data from the EMaBS trial (Figure 2) give an estimated eligibility fraction (proportion eligible of those 
Table 2 Characteristics showing differences between EMaBS children and community survey children after multivariable analysis

\begin{tabular}{|c|c|c|}
\hline Sociodemographic variables & Adjusted OR $(95 \% \mathrm{Cl})^{1}$ & $P^{1}$ \\
\hline \multicolumn{3}{|l|}{ Maternal tribe } \\
\hline Muganda & 1 & 0.03 \\
\hline Munyankole/Mutoro/Munyarwanda & $0.31(0.14,0.71)$ & \\
\hline Musoga & $0.44(0.14,1.32)$ & \\
\hline Other & $0.76(0.36,1.61)$ & \\
\hline \multicolumn{3}{|l|}{ Maternal education } \\
\hline None & $5.89(2.28,15.17)$ & $<0.001$ \\
\hline Primary & 1 & \\
\hline Secondary & $2.07(1.21,3.55)$ & \\
\hline Tertiary & $0.97(0.31,3.03)$ & \\
\hline \multicolumn{3}{|l|}{ Paternal education } \\
\hline None/primary & 1 & $<0.001$ \\
\hline Secondary & $0.64(0.33,1.23)$ & \\
\hline Tertiary & $0.18(0.08,0.40)$ & \\
\hline \multicolumn{3}{|l|}{ Maternal employment } \\
\hline Unemployed & 1 & \\
\hline Employed & $0.21(0.12,0.37)$ & $<0.001$ \\
\hline \multicolumn{3}{|l|}{ Crowding } \\
\hline$<=3$ people/room & 1 & \\
\hline >3 people/room & $0.54(0.30,0.97)$ & 0.04 \\
\hline \multicolumn{3}{|l|}{ Walls } \\
\hline Bricks & 1 & \\
\hline Mud/metal & $0.28(0.11,0.73)$ & 0.01 \\
\hline \multicolumn{3}{|l|}{ Barefoot exposure } \\
\hline Never/rarely & 1 & \\
\hline Often & $17.91(6.82,47.07)$ & $<0.001$ \\
\hline \multicolumn{3}{|l|}{ Child sleeps under net } \\
\hline Always & 1 & 0.02 \\
\hline Sometimes & $2.09(0.88,4.98)$ & \\
\hline Never & $3.66(1.42,9.47)$ & \\
\hline \multicolumn{3}{|l|}{ Household nets treated? } \\
\hline None & 1 & \\
\hline Some/all & $0.07(0.03,0.17)$ & $<0.001$ \\
\hline \multicolumn{3}{|l|}{ Measles } \\
\hline No & 1 & \\
\hline Yes & $0.23(0.07,0.80)$ & 0.02 \\
\hline
\end{tabular}

${ }^{1}$ Odds ratios use the trial population as the reference group and are adjusted for clustering. Results for tribe, maternal education and paternal education adjusted for each other; results for maternal employment adjusted for tribe and parental education; results for crowding and walls adjusted for tribe, education, employment and each other; results for barefoot exposure, child bed-net usage and household net treatment adjusted for all other factors except measles; results for measles adjusted for all other factors. screened) of $23 \%$ and an estimated enrolment fraction (proportion randomized of those eligible) of 98\%, yielding a recruitment fraction of $22 \%$. As far as we are aware, there is no clear consensus on an acceptable level of trial participation of eligible persons when reviewed at the community level, with most studies focusing on recruitment ratios at the level of the point of recruitment or primary care [22,25-27]. It is therefore difficult to assess the uptake rate in this trial in context and this is an area in need of further study.

Whilst the majority maternal tribe in both groups was the local Baganda, the proportion within the trial participants was $15 \%$ less than within the community at large. The difference was largely made up by a higher proportion of mothers from the Banyankole and Luo tribes. The Banyankole are a Western Ugandan tribe and the Luo are from Northern Uganda [38]. The possibility of differences between the trial and community children, based on differences due to ethnic origin, therefore exists. Representation of minority ethnic groups in clinical trials is usually an issue of under-representation, with consequent difficulty extrapolating results to these groups [21,35,36,39-41]. It is therefore reassuring that none of the minority tribes for this region were underrepresented in the trial compared to the community.

Children enrolled in the trial were more likely to be from families of higher socioeconomic status. Maternal employment status and income were higher, as was the level of both maternal and paternal education. There was a difference in crowding status, with trial children more likely to live in crowded circumstances. It is suggested that increased crowding may be a function of increased wealth in some circumstances. In particular it may be the case that families with increased income remain in their current property, but members of extended family or friends may move into the residence. This is consistent with findings from other settings, where in general, trial participation is more likely amongst those of higher socioeconomic status [22,24,33,35,40]. These differences might have implications for the trial results because worm burden is directly related to poverty [42], and in this study population, the mother's education was associated with a lower prevalence for every infection in mothers at enrolment [43]. Hence if, as seems possible, the helminth burden in the trial population was lower than that in the general community, the effect of the anthelminthic treatment intervention on trial outcomes would have been attenuated in the trial population compared to the theoretical effect of such an intervention applied to the whole community.

In general, disease exposure risks were fewer amongst the trial children with more bed-net use and less barefoot exposure. This difference persisted after adjustment for parental socioeconomic status. It may be the case that a 


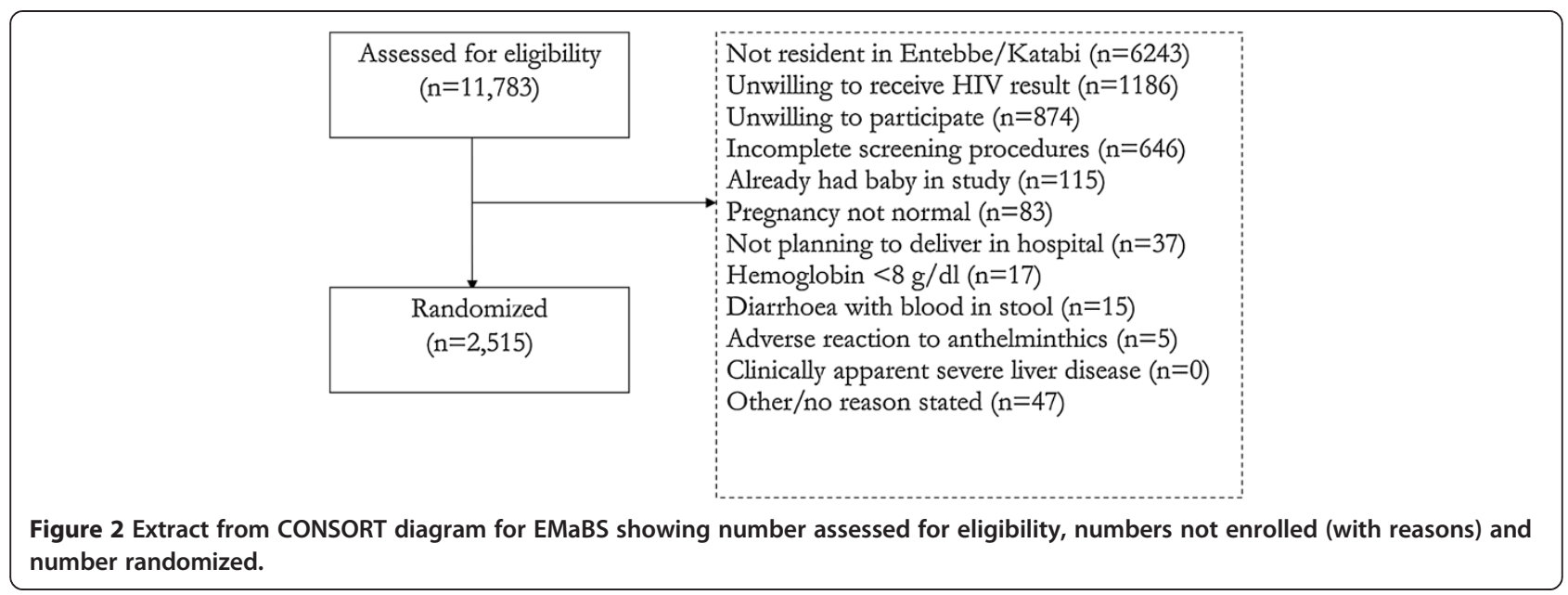

systemic bias in selection for children in the trial resulted in selection of children with lower risk exposure status (not mediated by parental socioeconomic status). Alternatively, health education as part of the trial may have led to less exposure prone behaviour in the families of the trial children. However, importantly, with the exception of measles, there were no differences between the two groups in terms of reported episodes of infectious diseases, one of the EMaBS primary outcomes. This suggests that the sociodemographic differences we have observed between trial and community survey participants would not have led to biased intervention effect estimates on this primary outcome in the EMaBS trial.

\section{Strengths and limitations}

We were unable to select participants at the level of the child due to the lack of sampling frame and therefore used a multi-stage sampling survey approach. This was done using a predefined random sampling approach and was taken into account in the analysis, however, it is possible that our sampling strategy will have over-represented children in less populated areas. There may be important differences between these children and children in more populous areas, hence potentially biasing our results. The fact that we used a random sampling approach should have reduced bias in the sample, however the clustered nature of our design means we may have misrepresented variables which are geographically confined. For example, there was one sampled area (a military barracks) which we were not permitted to enter, whereas children enrolled in the trial do live in this area. Indeed, this may explain the higher proportion of abodes constructed from metal amongst the trial children, as this is the predominant material used in military barracks in Entebbe.

The high response rate in the community survey means that selection bias should be minimized, and data completeness for the community survey was high. For the trial children we used several different sources of information, meaning the completeness of the data for each variable differed. In particular, a number of variables that were assessed from the supplementary forms for EMaBS children are limited because out of the 199 children assessed, only 128 supplementary forms were completed. There is no reason to believe this introduced bias since characteristics of the children who completed forms were similar to those of the children who did not, however, it limited the study's power to detect differences between the groups for these variables. It is possible that responses to the questions may have been systematically different between the trial and community-surveyed groups. This may have occurred because the interviewers in the trial clinic and the community were different throughout. Also, the parents or guardians of the non-trial children may have responded to questions on recent childhood illnesses differently to the parents or guardians of the trial children, for instance, participation in the trial may have sensitized them to keeping a more accurate record of their child's illnesses. We included trial children in our community survey (five children provided data to both the trial and community survey during the study period) and whilst this was intended in the survey design on the basis that they are part of their community and thus not as such a limitation, it could have led to a slight underestimation of the differences between the groups.

\section{Conclusions}

Recruitment at the level of the antenatal clinic did not achieve enrolment of all eligible participants into this trial and this was unlikely to be fully explained by refusal or exclusion criteria. The study population was significantly different from the community at large on the basis of ethnic composition and socioeconomic status. There appeared to be increased disease risk factors in the community survey group but little difference in terms of reported disease episodes. To our knowledge, this is the first study of its kind using a community survey to assess the external validity 
of a randomized controlled trial. External validity is a very important component of the assessment of trials and this approach offers a cost-effective, practical and robust method of assessing the validity of a trial.

\section{Abbreviations}

Cl: Confidence interval; EMaBS: Entebbe Mother and Baby Study; GIS: Geographic information system; HIV: Human immunodeficiency virus; km: Kilometer; OR: Odds ratio.

\section{Competing interests}

The authors declare that they have no competing interests.

\section{Authors' contributions}

$J M$ drafted this manuscript with contributions from EW and AE. JM, EW and LM contributed to statistical analysis and data management. JM and MS conducted data acquisition in the community, JN led the clinic team in data acquisition from the trial participants. JM and AE conceived and designed the study, and AE supervised JM in conducting the study. All authors read and approved the final manuscript.

\section{Acknowledgements}

We thank all staff and participants of the Entebbe Mother and Baby Study, and the community field team in Entebbe and Katabi. We thank Cally Tann, Jim Todd and Patrick Woodburn for contributions to the planning of the study. The study was funded by Wellcome Trust grant numbers 064693 and 079110. E Webb was supported in part by the UK Medical Research Council.

\section{Author details}

${ }^{1}$ Department of Global Health, Division of Clinical Medicine, Brighton and Sussex Medical School, Falmer, Brighton BN1 9PX, UK. ${ }^{2}$ Medical Research Council, Uganda Virus Research Institute, PO Box 49, Entebbe, Uganda. ${ }^{3}$ London School of Hygiene and Tropical Medicine, Keppel Street, London WC1E 7HT, UK

Received: 31 January 2014 Accepted: 18 July 2014

Published: 6 August 2014

\section{References}

1. Guyatt GH, Sackett DL, Cook DJ: Users' Guides to the Medical Literature II. How to use an article about therapy or prevention A. Are the results of the study valid? JAMA 1993, 270:2598-2601.

2. Guyatt GH, Sackett DL, Cook DJ: Users' Guides to the Medical Literature II. How to use an article about therapy or prevention B. What were the results and will they help me in caring for my patients? JAMA 1994, 271:59-63.

3. Klesges $L M$, Dzewaltowski DA, Glasgow RE: Review of external validity reporting in childhood obesity prevention research. Am J Prev Med 2008, 34:216-223.

4. Joussen AM, Lehmacher W, Hilgers RD, Kirchhof B: Is significant relevant? Validity and patient benefit of randomized controlled clinical trials on age-related macular degeneration. Surv Ophthalmol 2007, 52:266-278.

5. Ricci S, Celani MG, Righetti E: Development of clinical guidelines: methodological and practical issues. Neurol Sci 2006, 27(Suppl 3):S228-S230.

6. Green LW, Glasgow RE: Evaluating the relevance, generalization, and applicability of research: issues in external validation and translation methodology. Eval Health Prof 2006, 29:126-153.

7. Siderowf AD: Evidence from clinical trials: can we do better? NeuroRx 2004, 1:363-371.

8. Bellomo R, Bagshaw SM: Evidence-based medicine: classifying the evidence from clinical trials the need to consider other dimensions. Crit Care 2006, 10:232.

9. Evans JG: Evidence-based and evidence-biased medicine. Age Ageing 1995, 24:461-463.

10. Schulz KF, Altman DG, Moher D, CONSORT group: CONSORT 2010 statement: updated guidelines for reporting parallel group randomized trials. Ann Intern Med 2010, 152:726-732.

11. Atkins $D$, Best $D$, Briss PA, Eccles $M$, Falck-Ytter $Y$, Flottorp $S$, Guyatt $G H$ Harbour RT, Haugh MC, Henry D, Hill S, Jaeschke R, Leng G, Liberati A,
Magrini N, Mason J, Middleton P, Mrukowicz J, O'Connell D, Oxman AD, Phillips B, Schünemann HJ, Edejer TT, Varonen H, Vist GE, Williams JW, Stephanie Zaza S: Grading quality of evidence and strength of recommendations. BMJ 2004, 328:1490.

12. Guyat G, Gutterman D, Baumann MH, Addrizzo-Harris D, Hylek EM, Phillips B, Raskob G, Lewis S, Schunemann H: Grading strength of recommendations and quality of evidence in clinical guidelines: report from an american college of chest physicians task force. Chest 2006, 129:174-181.

13. Volmink J, Swingler G, Siegfried N: Where to practise evidence-based medicine? Lancet 2001, 357:724.

14. Bonell C, Oakley A, Hargreaves J, Strange V, Rees R: Assessment of generalisability in trials of health interventions: suggested framework and systematic review. BMJ 2006, 333:346-349.

15. Chinnock P, Siegfried N, Clarke M: Is evidence-based medicine relevant to the developing world? PLOS Med 2005, 2:e107.

16. Elliot AM, Kizza M, Quigley MA, Ndibazza J, Nampijja M, Muhangi L, Morison L, Namujju PB, Muwanga M, Kabatereine N, Whitworth JAG: The impact of helminths on the response to immunisation and on the incidence of infection and disease in childhood in Uganda: design of a randomised, double-blind, placebo-controlled, factorial trial of deworming interventions delivered in pregnancy and early childhood. Clin Trials 2007, 4:42-57.

17. Ndibazza J, Muhangi L, Akishule D, Kiggundu M, Ameke C, Oweka J, Kizindo R, Duong T, Kleinschmidt I, Muwanga M, Elliott AM: The effects of de-worming in pregnancy on maternal and perinatal outcomes in Entebbe Uganda: a randomised controlled trial. Clin Infect Dis 2010, -50:531-540.

18. Webb EL, Mawa PA, Ndibazza J, Kizito D, Namatovu A, Kyosiimire-Lugemwa J, Nanteza B, Nampijja M, Muhangi L, Woodburn PWW, Akurut H, Mpairwe H, Akello M, Lyadda N, Bukusuba J, Kihembo M, Kizza M, Kizindo R, Nabulime J, Ameke C, Namujju PB, Tweyogyere R, Muwanga M, Whitworth $J A G$, Elliott AM: Effect of single-dose anthelminthic treatment during pregnancy on an infant's response to immunization and on susceptibility to infectious diseases in infancy: a randomised, double-blind, placebo-controlled trial. Lancet 2011, 377:52-62.

19. Mpairwe H, Webb E, Muhangi L, Ndibazza J, Akishule D, Nampijja M, Ngom-wegi S, Tumusime J, Muwanga M, Rodrigues LC, Elliott AM: Anthelminthic treatment during pregnancy is associated with an increased risk of allergic conditions in infancy: results from a randomised controlled trial. Pediatr Allergy Immunol 2011, 22:305-312.

20. Ndibazza J, Mpairwe H, Webb EL, Mawa PA, Nampijja M, Muhangi L, Kihembo M, Lule SA, Rutebarika D, Apule B, Akello F, Akurut H, Oduru G, Naniima P, Kizito D, Kizza M, Kizindo R, Tweyongyere R, Alcock K, Muwanga $M$, Elliott AM: Impact of anthelminthics treatment in pregnancy and early childhood on response to immunisation and on the incidence of infectious diseases and eczema in early childhood: results of a randomised, double-blind, placebo-controlled trial. PLoS One 2012, 7:e50325.

21. Heiat A, Gross CP, Krumholz HM: Representation of the elderly, women, and minorities in heart failure clinical trials. Arch Intern Med 2002, 162:1682-1688.

22. Uijen AA, Bakx JC, Mokkink HG, van Weel C: Hypertension patients participating in trials differ in many aspects from patients treated in general practices. J Clin Epidemiol 2007, 60:330-335.

23. Khan AY, Preskorn SH, Baker B: Effect of study criteria on recruitment and generalizability of the results. J Clin Psychopharmacol 2005, 25:271-275.

24. Corrie $P$, Shaw J, Harris R: Rate limiting factors in recruitment of patients to clinical trials in cancer research: a descriptive study. BMJ 2003, 327:320-321.

25. Sokka T, Pincus T: Most patients receiving routine care for rheumatoid arthritis in 2001 did not meet inclusion criteria for most recent clinical trials or American College of Rheumatology criteria for remission. J Rheumatol 2003, 30:1138-1146.

26. Schneider LS, Olin JT, Lyness SA, Chui HC: Eligibility of Alzheimer's disease clinic patients for clinical trials. J Am Geriatr Soc 1997, 45:923-928.

27. Masoudi FA, Havranek EP, Wolfe P, Gross CP, Rathore SS, Steiner JF, Ordin DL, Krumholz HM: Most hospitalized older persons do not meet the enrollment criteria for clinical trials in heart failure. Am Heart J 2003, 146:250-257.

28. Braslow JT, Duan N, Starks SL, Polo A, Bromley E, Wells KB: Generalizability of studies on mental health treatment and outcomes, 1981 to 1996. Psychiatr Serv 2005, 56:1261-1268. 
29. Dzewaltowski DA, Estabrooks PA, Klesges LM, Bull S, Glasgow RE: Behavior change intervention research in community settings: how generalizable are the results? Health Promotion Int 2004, 19:235-245.

30. Van Spall HG, Toren A, Kiss A, Fowler RA: Eligibility criteria of randomized controlled trials published in high-impact general medical journals: a systematic sampling review. JAMA 2007, 297:1233-1240.

31. Gross CP, Mallory R, Heiat A, Krumholz HM: Reporting the recruitment process in clinical trials: who are these patients and how did they get there? Ann Intern Med 2002, 137:10-16.

32. Gross CP, Garg PP, Krumholz HM: The generalizability of observational data to elderly patients was dependent on the research question in a systematic review. J Clin Epidemiol 2005, 58:130-137.

33. Fosså SD, Skovlund E: Selection of patients may limit the generalizability of results from cancer trials. Acta Oncol 2002, 41:131-137.

34. Bijker N, Peterse JL, Fentiman IS, Julien J-P, Hart AAM, Avril A, Cataliotti L, Rutgers EJT: Effects of patient selection on the applicability of results from a randomised clinical trial (EORTC 10853) investigating breast conserving therapy for DCIS. Br J Cancer 2002, 87:615-620.

35. Bartlett C, Davey P, Dieppe P, Doyal L, Ebrahim S, Egger M: Women, older persons, and ethnic minorities: factors associated with their inclusion in randomised trials of statins 1990 to 2001. Heart 2003, 89:327-328.

36. Lee PY, Alexander KP, Hammill BG, Pasquali SK, Peterson ED:

Representation of elderly persons and women in published randomized trials of acute coronary syndromes. JAMA 2001, 286:708-713.

37. Tann CJ, Kizza M, Morison L, Mabey D, Muwanga M, Grosskurth H, Elliot AM: Use of antenatal services and delivery care in Entebbe, Uganda: a community survey. BMC Pregnancy Childbirth 2007, 7:23.

38. Uganda Bureau of Statistics: The 2002 Uganda Population and Housing Census, Population Composition; October 2006. Kampala, Uganda: Uganda Bureau of Statistics; 2002

39. Rothwell PM: Factors that can affect the external validity of randomised controlled trials. PLoS Clin Trials 2006, 1:e9.

40. Bartlett C, Doyal L, Ebrahim S, Davey P, Bachmann M, Egger M, Dieppe P. The causes and effects of socio-demographic exclusions from clinical trials. Health Technol Assess 2005, 9:1-152.

41. Rathore SS, Krumholz HM: Race, ethnic group, and clinical research. BMJ 2003, 327:763-764.

42. Bethony J, Brooker S, Albonico M, Geiger S, Loukas A, Diemert D, Hotez PJ: Soil-transmitted helminth infections: ascariasis, trichuriasis, and hookworm. Lancet 2006, 367:1521-1532.

43. Woodburn PW, Muhangi L, Hillier S, Ndibazza J, Namuiju PB, Kizza M Ameke C, Omoding NE, Booth M, Elliott AM: Risk factors for helminth, malaria, and HIV infection in pregnancy in Entebbe, Uganda. PLOS Negl Trop Dis 2009, 3:e473.

\section{doi:10.1186/1745-6215-15-310}

Cite this article as: Millard et al:: Assessing the external validity of a randomized controlled trial of anthelminthics in mothers and their children in Entebbe, Uganda. Trials 2014 15:310.

\section{Submit your next manuscript to BioMed Central and take full advantage of:}

- Convenient online submission

- Thorough peer review

- No space constraints or color figure charges

- Immediate publication on acceptance

- Inclusion in PubMed, CAS, Scopus and Google Scholar

- Research which is freely available for redistribution

Submit your manuscript at www.biomedcentral.com/submit
C Biomed Central 